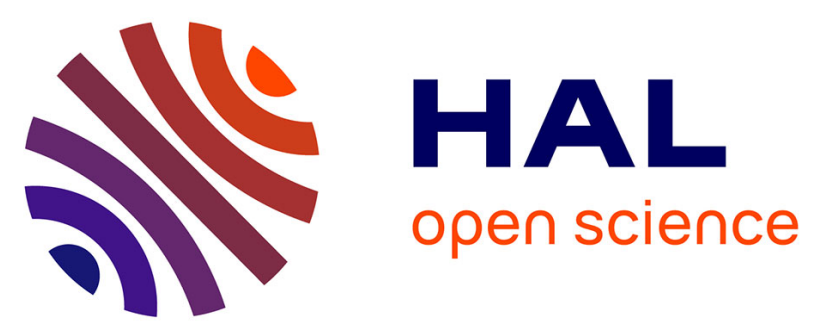

\title{
Predictive model for microvascular invasion of hepatocellular carcinoma among candidates for either hepatic resection or liver transplantation
}

Hidetoshi Nitta, Marc-Antoine Allard, Mylène Sebagh, Vincent Karam, Oriana Ciacio, Gabriella Pittau, Eric Vibert, Antonio Sa Cunha, Daniel Cherqui, Denis Castaing, et al.

\section{To cite this version:}

Hidetoshi Nitta, Marc-Antoine Allard, Mylène Sebagh, Vincent Karam, Oriana Ciacio, et al.. Predictive model for microvascular invasion of hepatocellular carcinoma among candidates for either hepatic resection or liver transplantation. Surgery, 2019, 165, pp.1168 - 1175. 10.1016/j.surg.2019.01.012 . hal-03485965

\section{HAL Id: hal-03485965 \\ https://hal.science/hal-03485965}

Submitted on 20 Dec 2021

HAL is a multi-disciplinary open access archive for the deposit and dissemination of scientific research documents, whether they are published or not. The documents may come from teaching and research institutions in France or abroad, or from public or private research centers.
L'archive ouverte pluridisciplinaire HAL, est destinée au dépôt et à la diffusion de documents scientifiques de niveau recherche, publiés ou non, émanant des établissements d'enseignement et de recherche français ou étrangers, des laboratoires publics ou privés.

\section{(ㄷ)(1) $\$$}

Distributed under a Creative Commons Attribution - NonCommerciall 4.0 International 
1 Predictive model for microvascular invasion of hepatocellular carcinoma among

2 candidates for either hepatic resection or liver transplantation

4 Hidetoshi Nitta, MD, PhD, FACS ${ }^{* \S}$ Marc-Antoine Allard, MD, * Mylène Sebagh,

$5 \mathrm{MD}^{\dagger}$ Vincent Karam, $\mathrm{PhD}^{*}$ Oriana Ciacio, MD, ${ }^{*}$ Gabriella Pittau, MD, ${ }^{*}$ Eric Vibert,

$6 \mathrm{MD}, \mathrm{PhD},{ }^{*}$ Antonio Sa Cunha, MD, ${ }^{*}$ Daniel Cherqui, MD, ${ }^{*}$ Denis Castaing, MD,

7 Henri Bismuth, MD, PhD, ${ }^{*}$ Catherine Guettier, MD, PhD $¥$ Didier Samuel, $\mathrm{MD}, \mathrm{PhD}, *$

8 Hideo Baba, MD, PhD, FACS ${ }^{\S}$ and René Adam, MD, PhD, ${ }^{*}$

9

$10{ }^{*}$ The Centre Hépato-Biliaire, AP-HP, Hôpital Paul Brousse, Univ Paris Sud, Inserm U

11935 and U 1193, Villejuif, France

$12 \dagger$ Departement of Pathology, Paul Brousse Hospital, Assistance Publique-Hôpitaux de

13 Paris, Villejuif, France

$14 \ddagger$ Department of Pathology, Bicêtre University Hospital, University of Paris-Sud

$15 \S$ Department of Gastroenterological Surgery, Graduate School of Life Sciences,

16 Kumamoto University, Japan

17

18 Correspondence and reprint requests should be addressed to: Hidetoshi Nitta, Centre 
19 Hépato-Biliaire, 9 Avenue Paul Vaillant Couturier, 94804 Villejuif, France.

20 Tel: +33 1455930 49; Fax: +33 1455938 57; E-mail: hnitta5085@ gmail.com

21 The authors declare no conflict of interest

22 Original article

23 


\section{Abstract}

25 Background: Microvascular invasion (MVI) is the strongest prognostic factor of survival in patients with hepatocellular carcinoma (HCC). We therefore developed a predictive model for MVI of HCC, to help guide treatment strategies in patients scheduled for either hepatic resection (HR) or liver transplantation (LT).

Methods: HCC patients who underwent HR or LT from 1994 to 2016 were divided into training and validation cohorts. A predictive model for MVI was developed based on MVI risk factors in the training cohort, and validated in the validation cohort.

Results: A total of 910 patients (425 HR, $485 \mathrm{LT})$ were included in the training ( $\mathrm{n}=637)$ and validation $(\mathrm{n}=273)$ cohorts. Multivariate analysis identified alfa-fetoprotein $\geq 100$ ng/ml (relative risk [RR] 3.05, $P<0.0001)$, tumor size $\geq 40 \mathrm{~mm}(\mathrm{RR} 1.98, P=0.0002)$, non-boundary HCC type (RR 1.91, $P=0.001$ ), neutrophil-to-lymphocyte ratio (RR 1.86, $P=0.002)$, and aspartate aminotransferase $(\mathrm{RR} 1.53, P=0.02)$ as associated with MVI. The estimated probability of MVI ranged from $17.0 \%$ in patients with none of these factors to $86.9 \%$ in the presence of all factors. This model achieved a C-index of 0.732 in the validation cohort. The 5 -year overall survival of patients with $\geq 50 \%$ probability of MVI was poorer than that of patients with $<50 \%$ probability (HR; $39.1 \%$ vs $61.2 \%, P$ $<0.0001$, LT; 5-year OS, $54.8 \%$ vs $79.0 \%, P=0.05)$.

Conclusion: This model developed from preoperative data allows reliable prediction of 
43 MVI and may help with preoperative decisions regarding the suitability of HR or LT in

44 patients with HCC. in candidates for either HR or LT.

45

46

47

48 


\section{Introduction}

Microvascular invasion (MVI) of hepatocellular carcinoma (HCC) is a significant poor risk prognostic factor of survival in patients undergoing hepatic resection (HR) and liver transplantation (LT) $)^{1-4}$, and a better predictor of tumor recurrence and overall survival

53 (OS) than the commonly used Milan criteria ${ }^{5}$. However, MVI is only diagnosed by pathological examination after HR or LT, and is impossible to predict preoperatively. Given that the probability of preoperative MVI may influence the choice of surgical strategy and allow the selection of patients likely to benefit from HR or LT, it is necessary to develop a more accurate predictive model for MVI. diffusion-weighted magnetic resonance imaging (MRI) images, as well as genetic markers, may help to predict $\mathrm{MVI}^{6-9}$. However, studies of these techniques have included limited numbers of patients, and furthermore, the costs and expertise required

62 by these techniques may inhibit their routine use. A predictive model of MVI based on easily available factors and imaging techniques may thus offer a more practical and useful approach. status, and liver function ${ }^{10,11}$; HR is generally considered when the tumor status and 
67 liver function are favorable, while LT may be preferred when the liver function is unfavorable and tumor status less advanced. Most risk models for MVI are adapted for

69 either HR or $\mathrm{LT}^{2}$, but not all patients can be clearly assigned to one of these approaches because of their background, tumor status, liver function, and organ shortage. A predictive model for MVI that could be used to guide treatment strategies in patients scheduled for either HR or LT would therefore be a valuable tool. This study therefore aimed to identify independent predictors of MVI and establish a user-friendly model to predict MVI based on preoperative factors in candidates for either HR or LT. We then sought to assess the value of our model in a validation cohort.

\section{Patients and Methods}

\section{Patient Population}

We enrolled included 1051 consecutive patients diagnosed with HCC preoperatively, who underwent HR (n=490) or LT $(n=561)$ at the Paul Brousse Hospital, Villejuif, France, between January 1994 and June 2016. We excluded patients who were diagnosed as not having HCC by pathological examination $(n=74)$, underwent R2 resection $(n=5)$, had macrovascular invasion $(n=48)$, or who had insufficient data $(n=14)$.

84 The remaining 910 patients were included in the study. Patients diagnosed with HCC 
85 preoperatively were included, even if they underwent pretreatment before HR or LT.

86 Patients who underwent surgery between January 1994 and June 2012 were assigned to

87 the training cohort $(n=637)$ and those who underwent surgery between July 2012 and

88 May 2016 were assigned to the validation cohort $(n=273)$. The median follow-up time

89 for the training cohort was 86.3 months (HR patients, 59.0 months; LT patients, 116.5

90 months).

91

92 Preoperative Diagnosis and Treatment

93 HCC diagnosis was based on imaging data (ultrasound, contrast-enhanced computed

94 tomography [CE-CT], and MRI), serum alfa-fetoprotein (AFP), and clinical parameters

95 according to recent international guidelines ${ }^{12}$. The optimal treatment strategies for HCC

96 patients were determined at multidisciplinary meetings involving surgeons, oncologists,

97 hepatologists, and radiologists. Patients with single, peripheral tumors and compensated

98 liver function were usually selected to undergo HR and RO resection, whereas patients

$99 \quad$ Patients with multiple tumors with unpreserved liver function or severe portal

100 hypertension were proposed for LT, as described previously ${ }^{13}$. 
103 All clinical parameters, including hematological and biochemical findings and tumor

104 markers, were obtained within 1 month before surgery. The largest tumor size and

105 tumor number preoperatively were based on preoperative CE-CT. For patients who

106 underwent pretreatment, the clinical parameters and the radiological images were

107 obtained at the latest date before surgery after pretreatment. The largest tumor gross

108 shape was evaluated by experienced radiologists based on CE-CT, and classified into

109 one of four types based on gross morphological appearance. Tumor shapes that were not

110 evaluable by CE-CT due to lipiodol deposition after transcatheter arterial

111 chemoembolization (TACE) were evaluated by MRI. The types were defined as

112 follows: type 1, single nodular type with round or oval shape with a clear boundary,

113 with or without fibrous pseudocapsule; type 2, single nodular type with extranodular

114 growth roughly resembling type 1 but with varying degrees of local extranodular

115 growth; type 3, confluent multinodular type comprising a cluster of small and confluent

116 nodules, each with a clear margin or capsule, and the tumor lobulated as a whole; and

117 type 4 , infiltrative type with irregular shape and unclear border ${ }^{14,15}$. We defined type 1

118 as boundary type and types $2-4$ as non-boundary types. 
121 All pathological specimens were routinely examined by two pathologists (CG, MS) who

122 were experts in liver tumor pathology. Specimens were cut into 5-mm thick slices. For

123 tumors $<2 \mathrm{~cm}$, nodules were sampled in their entirety; for larger lesions, nodules were

124 sampled extensively from the center to the periphery, with the number of samples at the

125 discretion of the pathologist. Sections were stained with hematoxylin-eosin-safran. MVI

126 was defined when cancer cells were present within the lumens of veins and venules. In

127 the event of any uncertainty, tumoral invasion was confirmed by immunohistochemistry

128 using a vascular antibody (CD34, D240).

129

130 Statistical Analysis

131 Categorical variables were compared using $\chi^{2}$ or Fisher's exact tests. Continuous variables were shown as mean \pm standard deviation, and compared using MannWhitney U tests. Cut-off values for continuous factors were determined based on receiver-operating characteristic (ROC) curve analysis. There were no missing data for most variables among the training cohort, except for

136 hepatitis B virus-DNA $(n=16,2.5 \%)$, hepatitis $C$ virus-RNA $(n=78,12.2 \%)$, body mass index $(n=19,3.0 \%)$, platelet count $(n=8,1.3 \%)$, albumin $(n=37,5.8 \%)$, neutrophil-to-lymphocyte ratio (NLR) $(\mathrm{n}=35,5.5 \%)$, creatinine $(\mathrm{n}=6,0.9 \%)$, 
139 gamma-glutamyltransferase ( $\mathrm{n}=11,1.7 \%)$, alkaline phosphatase (ALP) $(\mathrm{n}=27,4.2 \%)$,

140 alanine aminotransferase (ALT) $(n=2,0.3 \%)$, and boundary-type on CT $(n=90,14.1 \%)$.

141 The exclusion of patients with missing data might lead to biased risk estimates ${ }^{16,17}$ and

142 multiple imputation $(\mathrm{N}=20)$ was therefore performed for all multivariate analyses using

143 the R package (mice). There were no missing data in the validation cohort. Each of the

144 imputed datasets $(\mathrm{n}=20)$ was analyzed separately using a multivariable Cox regression

145 or logistic regression model and pooled to identify independent predictors of survival or

146 MVI, respectively. Variables with a $P$ value of $<0.20$ in univariate analysis were

147 subjected to multivariate analysis using Cox proportional hazards and logistic

148 regression models. All variables associated with prognosis and MVI were candidates

149 using a stepwise backward elimination procedure with a threshold of $P<0.05$. The

150 level of significance for all tests was set at $P<0.05$. The probabilities of MVI in the

151 predictive model were calculated based on the coefficients obtained in the multivariate

152 logistic regression model. The predictive performance of the model was measured by

153 the concordance index (C-index) and calibration with 400 bootstrap samples.

154 Cumulative everall survival (OS) and recurrence-free survival (RFS) curves were

155 obtained using the Kaplan-Meier method. The OS and RFS rates after surgery were estimated by the log-rank test. Survival time was calculated from the date of HR or LT 
to the date of the event of interest, or the date of last follow-up. To estimate RFS,

158 patients without evidence of recurrence were censored at the time of last follow-up or

159 death. All statistical analyses were performed using JMP ver.12 (SAS Institute, Cary,

$160 \mathrm{NC}, \mathrm{USA}$ ), R version 3·1.1. and the R package (mice).

162 Results

163 Risk Factors for Prognosis in Training Cohort and Outcomes with or without

\section{Microvascular Invasion}

165 The backgrounds of the patients in the training and validation cohorts are shown in

166 supplementary Table 1 . We initially evaluated the risk factors for poor OS and RFS

167 among the training cohort (Table 1). In patients who underwent HR, MVI was an

168 independent risk factor for OS (relative risk [RR], 2.51; 95\% confidence interval [C],

$169 \quad 1.63-3.87 ; P<0.0001$ hazard ratio, $2.63 ; 95 \%$ confidence interval $[\mathrm{CI}], 1.72-4.05 ; P$

$170<0.0001)$ and RFS (RR, 1.58; 95\%CI, $1.03 \quad 2.43 ; P=0.04$ hazard ratio, $1.98 ; 95 \% \mathrm{CI}$,

$171 \quad 1.44-2.70 ; P<0.0001)$. MVI was also an independent risk factor for OS (RR, 2.01;

$17295 \% \mathrm{CI}, 1.42 \quad 2.83 ; P<0.0001$ hazard ratio, $2.35 ; 95 \% \mathrm{CI}, 1.69-3.27 ; P<0.0001)$ and

173 RFS (RR, 3.07; 95\% CI, 1.63 5.79; $P=0.0005$ hazard ratio, 3.22; 95\% CI, 1.73-6.17; $P$

$174=0.0002)$ in patients who underwent LT. The Kaplan-Meier curve according to MVI is 
175 shown in Fig 1. The 5-year OS and RFS in patients who underwent HR were

176 significantly different with and without MVI (OS, 38.4\% vs 66.1\%, $P<0.0001$; RFS,

$177 \quad 15.8 \%$ vs $28.6 \%, P<0.0001$, respectively). The 5-year OS and RFS in patients who

178 underwent LT with and without MVI were 51.4 vs $80.6 \%$, and $60.9 \%$ vs $89.9 \%$,

179 respectively (OS, $P<0.0001$; RFS, $P<0.0001)$.

180

181 Preoperative Risk Factors for MVI after HR or LT in the Training Cohort

182 All variables in this univariate analysis were based on data obtained preoperatively.

183 Univariate analysis identified eight preoperative factors associated with MVI after HR

184 and LT: previous TACE, platelet count, NLR, ALP, AST, AFP, largest tumor size on

185 preoperative imaging, tumor number on preoperative imaging $>3$, and non-boundary

186 type (Table 2). Multivariate analysis identified five independent predictors for MVI:

187 AFP $\geq 100 \mathrm{ng} / \mathrm{ml}(\mathrm{RR}, 3.05 ; 95 \% \mathrm{CI}, 1.98-4.70 ; P<0.0001)$, largest tumor size in image

$188 \geq 40 \mathrm{~mm}(\mathrm{RR}, 1.98 ; 95 \% \mathrm{CI}, 1.38-2.84 ; P=0.0002)$, non-boundary type $(\mathrm{RR}, 1.91$;

95\%CI, 1.29-2.82; $P=0.001), \mathrm{NLR} \geq 3.2(\mathrm{RR}, 1.86 ; 95 \% \mathrm{CI}, 1.26-2.75 ; P=0.002)$, and

190 AST $\geq 62(\mathrm{RR}, 1.53 ; 95 \% \mathrm{CI}, 1.08-2.17 ; P=0.02)$ (Table 2$)$. In addition, the predictive

191 factors of MVI for each group underwent HR or LT, or patients without cirrhosis were

192 shown in supplementary Table 2. 
194 Development and Validation of Predictive Model for MVI Using Training Cohort

195 The predictive model was then developed using the previous five factors based on

196 logistic regression analysis (Table 3). The estimated probabilities (\%) for MVI were

197 thus weighted according to the RR for each of the five factors. The estimated

198 probability of MVI was $17.0 \%$ in patients without any factors, and increased to $86.9 \%$

199 in the presence of all factors. This predictive model was validated internally in the

200 training cohort using the bootstrap validation method, with a bootstrap-corrected

201 C-index of 0.710 . In addition, calibration plots for the probability of MVI showed good

202 calibration for the presence of MVI between the risk estimation according to the model

203 and histopathologic confirmation in surgical specimens (Fig. 2A).

206 The model was subsequently validated using the validation cohort. A calibration plot for

207 the probability of MVI showed good calibration between the model's predicted and actual observations (unadjusted C-index 0.750, 95\%CI, 0.683-0.805; bootstrap-corrected C-index 0.732) (Fig. 2B). When the validation cohort was divided

210 into patients who underwent HR and those who underwent LT, the bootstrap-corrected 
211 C-indexes were 0.691 and 0.798 , respectively, indicating good concordances in both

212 groups (Fig. 2C, D). Moreover, when the validation cohort was divided into patients

213 within and beyond the Milan criteria, the bootstrap-corrected C-indexes were 0.749 and

214 0.796, respectively (supplementary Fig 1A, B). The C-index of Child-Pugh A, and B or

215 C were 0.759 and 0.760 , respectively (supplementary Fig 1C, D).

216 The relationships between MVI probabilities and actual MVI rates confirmed by

217 pathological examination are summarized in Table 4. The MVI probabilities

218 corresponded closely with the actual MVI rates.

Outcomes of Patients with High or Low MVI Probabilities

221 We evaluated the outcomes of HCC patients according to MVI probability in the training cohort. The optimal cut-off value for MVI probability was $49.0 \%$ according to ROC analysis (area under the curve, 0.721 ). We therefore compared the prognoses of patients with MVI probabilities $<50 \%$ and $\geq 50 \%$. Among patients who underwent $\mathrm{HR}$, the 5-year OS and RFS rates in patients with MVI probability $\geq 50 \%$ were significantly

226 lower than those of patients with MVI probability <50\%. (5-year OS, 39.1\% vs $61.2 \%$, underwent LT, there was no significant difference in OS between patients with MVI 
229 probabilities $\geq 50 \%$ and $<50 \%$ (5-year OS,54.8 \% vs $79.0 \%, P=0.05$ ), but the 5-year

230 RFS in patients with an MVI probability $\geq 50 \%$ was significantly poorer than in patients

231 with an MVI probability <50\% (5-year RFS, 61.2\% vs 88.2\%, $P<0.0001$ ) (Fig. 3C, D).

232 When the training cohort was divided into patients within and beyond the Milan criteria,

233 the outcomes of patients with an MVI probability $\geq 50 \%$ was worse than that of patients

234 with MVI probability <50\% (supplementary Fig 2).

235

236 Comparison of predictive powers

237 The predictive powers of MVI in our predictive model, the other predicting model

238 (artificial neural network ${ }^{18}$ ), and the LT criteria (Milan criteria, UCSF criteria, and AFP

239 model $^{19}$ ) were compared by ROC curve analysis in the validation cohort. The area under

240 ROC curve of our model was significantly better than those of the other models among

241 either patients who underwent HR or patients who underwent LT (Supplementary Fig.

$2423)$. 


\section{Discussion}

244 The results of this study showed that the risk of death or recurrence in patients with

245 MVI, which accounted for about $40 \%$ of all patients, was two to three times higher than

246 in patients without MVI who underwent HR or LT. Preoperative evaluation of the

247 probability of MVI could thus influence the choice of surgical strategy. Multivariate

248 analysis identified five preoperative factors that were significantly associated with the

249 presence of MVI: AFP $\geq 100 \mathrm{ng} / \mathrm{ml}$, no-boundary type in CE-CT, NLR $\geq 3.2$, AST $\geq 62$,

250 and largest tumor size in CE-CT $\geq 40 \mathrm{~mm}$. The predictive model suggested that the

251 probability of MVI varied from $17.0 \%-86.9 \%$, depending on the combinations of these

252 five factors. The performance of this model was supported by C-index values of 0.710

253 and 0.732 in the training and validation cohorts, respectively, and by optimal calibration

254 curves demonstrating agreement between the predicted and actual observations.

Moreover, the predictive power for MVI of the model was significantly better than

those of the other MVI predicting model and LT criteria.

such as small sample sizes, and being limited to patients with early $\mathrm{HCC}$ or hepatitis B 
261 HCC preoperatively, and thus included patients with various tumor characteristics and

262 liver functions. The current study analyzed common datasets for patients who

263 underwent HR or LT, with the aim of establishing a predictive model appropriate for

264 eandidates for either HR or LT, given that because not all patients with HCC can be

265 clearly assigned to one of these approaches. The resulting predictive model

266 demonstrated high accuracy in patients with Child-Pugh A (C-index, 0.759), B or C

267 (C-index, 0.760) among the validation cohort, suggesting that it could be adopted for

268 patients with or without cirrhosis. Moreover, the high C-indexes for patients within

269 (0.749) and beyond the Milan criteria (0.796) also suggested that the predictive model

270 was suitable for both groups. Furthermore, the high C-indexes in patients who

271 underwent LT (0.798) and HR (0.691) suggested that the model may be useful for

272 helping to determine the optimal treatment strategy in both groups of patients.

273 In addition to tumor size and number, MVI should also be considered when choosing a

274 surgical strategy, because this is one of the strongest factors predicting poor prognosis

275 among patients undergoing HR or LT, even within the Milan criteria ${ }^{5,21,22}$. The

276 prognosis of patients with MVI who underwent LT was extremely poor (5-y OS, 51.4\%;

277 5-y RFS, 60.9\%). In particular, among the patients with MVI who underwent LT and

278 could be followed up for $>5$ years, the recurrence rate was as high as $52 \%$ (47/90) (data 
not shown). Therefore, it may be better to avoid upfront LT for patients who are more

280 likely to have MVI, not only because of the poor prognosis but also because of the

281 current organ shortage. The cut-off value based on MVI probability was $50 \%$, according

to ROC analysis. This cut-off value could be an important clinical indicator for deciding

283 on the treatment strategy for HCC. The outcomes of LT in patients with high MVI

284 probability $(\geq 50 \%)$ were extremely poor (5-year OS: 49.7\%; 5-year RFS: 48.0\%),

285 suggesting that these patients should not be considered for upfront LT, and neeadjuvant

therapies such as TACE or sorafenib may be needed to reduce the probability of MVI.

Jeong et al. reported that even in patients with concurrent HCC and MVI, TACE and

radiotherapy prior to LT showed acceptable oncologic outcomes ${ }^{23}$. AFP was the

value to less than $100 \mathrm{ng} / \mathrm{ml}$ without exacerbating other factors (tumor size, tumor shape,

NLR, and AST), the probability of MVI will be reduced as shown in Table 3. Halazun et

al. reported that the AFP response to locoregional therapies prior to LT was an

independent predictor of $\mathrm{RFS}^{2423}$. Therefore, locoregional therapy prior to LT may be

needed to reduce the probability of MVI and improve the prognosis for patients with 
297 in selecting good candidates for LT, and this may lead to an improved prognosis.

298 Patients with a $\geq 50 \%$ probability of MVI among patients who underwent HR showed

299 significantly poorer prognoses than those with $<50 \%$ probability (5-year OS: $42.4 \%$ vs

$30056.7 \%, P=0.001$ ). If liver function is preserved in patients with $\geq 50 \%$ probability,

301 anatomical HR or ensuring wide surgical margins is recommended, because of its

302 reported beneficial effect on the prognesis of patients with vaseular invasion ${ }^{2528}=$ There

303 is no consensus on how to undergo HR for HCC with MVI. However, in this study, the

304 rate of microsatellite lesions in patients with MVI was 47\% (118/251), which was

305 significantly higher than for patients without MVI $(23 \%, 89 / 386)(P<0.0001$, data not

306 shown). Zhou et al. reported that the required minimal length of the resection margin is

$307 \quad 6 \mathrm{~mm}$ to achieve 100\% micrometastasis clearance in the surrounding liver tissue for

$308 \quad \mathrm{HCC}^{24}$ Yamashita et al. reported that the disadvantage with the DFS rate for patients

309 with HCC with MVI could be removed by hepatic resection with a wide tumor margin

310 of $\geq 5 \mathrm{~mm}^{25}$. Although surgical margin is controversial, a wide surgical margin might be

311 one effective therapy for removing the main tumor with these satellite lesions or tumor

312 thrombi. We suggest that these concepts may even be adopted in patients within the

313 Milan criteria, because patients with a $\geq 50 \%$ probability had a poorer prognosis than

314 those with a $<50 \%$ probability, among patients meeting the Milan criteria. This model 
315 could therefore be used to calculate the MVI probability preoperatively, thus guiding

316 the choice of surgical strategy.

317 Tumor type has been classified using CE-CT ${ }^{14,15,26,27}$. In this study, we classified

318 tumor shape (boundary or non-boundary type) using CE-CT, because this method was

319 less ambiguous and a good predictor of gross classification. However, the Japanese

320 gross classification has also been used as a prognostic factor of survival and to predict

$321 \mathrm{MVI}^{28}$. Wu et al. reported that tumor shape reflected the incidence of MVI, using

322 various imaging techniques ${ }^{29}$, while He et al. also typed tumors according to shape

323 using CE-CT and associated them with MVI, with a similar accuracy to gross

324 classification of $65.3 \%^{14}$.

325 There were some limitations to the current study. First, it was a retrospective,

326 single-center study. Second, numerous imaging modalities are now available for

327 predicting MVI preoperatively, and contrast-enhanced ultrasound shows a significantly

328 higher correlation with gross classification than CE-CT $(86.9 \% \text { vs } 65.6 \%)^{30}$. Tumor

329 shape evaluated by gadolinium ethoxybenzyl diethylenetriamine pentaacetic

330 acid-enhanced MRI, or apparent diffusion coefficients evaluated by diffusion-weighted

331 MRI, could also be useful for predicting MVI ${ }^{7,31}$. The use of these imaging techniques

may improve the predictive accuracy for MVI, but more experience and skill may be 
333 required to implement them.

334

335 Conclusion

336 We developed a predictive model for MVI in patients with HCC, suitable for use in

337 potential candidates for either HR or LT, based on tumor size, AST, NLR, tumor

338 boundary, and AFP. This model could be a valuable tool in helping to decide treatment

339 strategies in HCC patients.

340

341

342 Acknowledgements

343 The authors declare no conflict of interest. We would like to thank Dr. V. Cailliez and K.

344 Murotani for statistical analyses.

345

346 


\section{Reference}

348 1. Vauthey JN, Lauwers GY, Esnaola NF, Do KA, Belghiti J, Mirza N, et al.

349 Simplified staging for hepatocellular carcinoma. J Clin Oncol. 2002;20:1527-1536.

2. Rodríguez-Perálvarez M, Luong TV, Andreana L, Meyer T, Dhillon AP, Burroughs

AK. A systematic review of microvascular invasion in hepatocellular carcinoma: diagnostic and prognostic variability. Ann Surg Oncol. 2013;20:325-339.

3. Mazzaferro V, Llovet JM, Miceli R, Bhoori S, Schiavo M, Mariani L, et al.

4. Shim JH, Jun MJ, Han S, Lee YJ, Lee SG, Kim KM, et al. Prognostic nomograms

5. Lim KC, Chow PK, Allen JC, Chia GS, Lim M, Cheow PC, et al. Microvascular

6. Shirabe K, Toshima T, Kimura K, Yamashita Y, Ikeda T, Ikegami T, et al. New 
scoring system for prediction of microvascular invasion in patients with hepatocellular carcinoma. Liver Int. 2014;34:937-941.

7. Suh YJ, Kim MJ, Choi JY, Park MS, Kim KW. Preoperative prediction of the microvascular invasion of hepatocellular carcinoma with diffusion-weighted imaging. Liver Transpl. 2012;18:1171-1178.

8. Banerjee S, Wang DS, Kim HJ, Sirlin CB, Chan MG, Korn RL, et al. A computed outcomes in hepatocellular carcinoma. Hepatology. 2015;62:792-800.

9. Yu YQ, Wang L, Jin Y, Zhou JL, Geng YH, Jin X, et al. Identification of serologic hepatocellular carcinoma. Nat Rev Clin Oncol. 2014;11:525-535. staging classification. Semin Liver Dis. 1999;19:329-338. 
12. Bruix J, Sherman M, Llovet JM, Beaugrand M, Lencioni R, Burroughs AK, et al. EASL Panel of Experts on HCC. Clinical management of hepatocellular carcinoma. Conclusions of the Barcelona-2000 EASL conference. European Association for the Study of the Liver. J Hepatol. 2001;35:421-430.

13. Adam R, Bhangui P, Vibert E, Azoulay D, Pelletier G, Duclos-Vallée JC, et al. Resection or transplantation for early hepatocellular carcinoma in a cirrhotic liver: does size define the best oncological strategy? Ann Surg. 2012;256:883-891.

14. He J, Shi J, Fu X, Mao L, Zhou T, Qiu Y, et al. The clinicopathologic and prognostic significance of gross classification on solitary hepatocellular carcinoma after hepatic resection. Medicine (Baltimore). 2015;94:e1331.

15. Fu X, Mao L, Tang M, Yan X, Qiu Y, He J, et al. Gross classification of solitary small hepatocellular carcinoma on preoperative computed tomography: Prognostic significance after radiofrequency ablation. Hepatol Res. 2016;46:298-305.

16. Harrell FE Jr, Lee KL, Mark DB. Multivariable prognostic models: issues in developing models, evaluating assumptions and adequacy, and measuring and reducing errors. Stat Med. 1996;15:361-387. 
17. Janssen KJ, Donders AR, Harrell FE Jr, Vergouwe Y, Chen Q, Grobbee DE, et al. Epidemiol. 2010;63:721-727.

18. Cucchetti A, Piscaglia F, Grigioni AD, Ravaioli M, Cescon M, Zanello M, et al. Hepatol. 2010;52:880-888.

19. Duvoux C, Roudot-Thoraval F, Decaens T, et al. Liver transplantation for

20. Lei Z, Li J, Wu D, Xia Y, Wang Q, Si A, et al. Nomogram for Preoperative performance of Milan criteria. Gastroenterology. 2012;143:986-994. Analysis of risk factors for tumor recurrence after liver transplantation for 
hepatocellular carcinoma: key role of immunosuppression. Liver Transpl. 2005;11:497-503.

22. Bertuzzo VR, Cescon M, Ravaioli M, Grazi GL, Ercolani G, Del Gaudio M, et al. $2011 ; 91: 1279-1285$.

24. Zhou XP, QuanZW, Cong WM, Yang N, Zhang HB, Zhang SH, et al.

23. Halazun KJ, Tabrizian P, Najjar M, Florman S, Schwartz M, Michelassi F, et al. Is it Time to Abandon the Milan Criteria?: Results of a Bicoastal US Collaboration to Redefine Hepatocellular Carcinoma Liver Transplantation Selection Policies. Ann Surg. 2018;268:690-699. for microinvasion of small hepatocellular carcinoma $\leq 2 \mathrm{~cm}$. Ann Surg Oncol. 2012;19:2027-2034. 
26. Kawamura Y, Ikeda K, Hirakawa M, Yatsuji H, Sezaki H, Hosaka T, et al. New classification of dynamic computed tomography images predictive of malignant characteristics of hepatocellular carcinoma. Hepatol Res. 2010;40:1006-1014.

27. Nakayama H, Takayama T, Okubo T, Higaki T, Midorikawa Y, Moriguchi M, et al. Proposal of objective morphological classification system for hepatocellular carcinoma using preoperative multiphase computed tomography. J Gastroenterol. 2014;49:1430-1437.

28. Kanai T, Hirohashi S, Upton MP, Noguchi M, Kishi K, Makuuchi M, et al. Pathology of small hepatocellular carcinoma. A proposal for a new gross classification. Cancer. 1987;60:810-819.

29. Wu TH, Hatano E, Yamanaka K, Seo S, Taura K, Yasuchika K, et al. A non-smooth tumor margin on preoperative imaging predicts microvascular invasion of hepatocellular carcinoma. Surg Today. 2016;46:1275-1281.

30. Hatanaka K, Minami Y, Kudo M, Inoue T, Chung H, Haji S. The gross classification of hepatocellular carcinoma: usefulness of contrast-enhanced US. $J$ Clin Ultrasound. 2014;42:1-8. 
444 31. Ariizumi S, Kitagawa K, Kotera Y, Takahashi Y, Katagiri S, Kuwatsuru R, et al. A

445 non-smooth tumor margin in the hepatobiliary phase of gadoxetic acid disodium

446 (Gd-EOB-DTPA)-enhanced magnetic resonance imaging predicts microscopic

447 portal vein invasion, intrahepatic metastasis, and early recurrence after

448 hepatectomy in patients with hepatocellular carcinoma. $J$ Hepatobiliary Pancreat

$449 \quad$ Sci. 2011;18:575-585.

450 
451 Table 1 Multivariate analysis of prognostic factors for overall and recurrence-free 452 survival among patients who underwent hepatic resection or transplantation (Cox 453 proportional hazard model)

454

455

\begin{tabular}{|c|c|c|c|c|}
\hline & & RR & $95 \% \mathrm{CI}$ & $p$ value \\
\hline \multirow[t]{5}{*}{ Hepatic resection OS } & MVI & 2.51 & $1.63-3.87$ & $<0.0001$ \\
\hline & Platelet $<10 \times 10^{4} / \mu 1$ & 1.90 & $1.10-3.29$ & $\theta .02$ \\
\hline & Creatinine $\geq 90 \mu \mathrm{mol} / 4$ & 1.77 & $1.10-2.86$ & 0.02 \\
\hline & Albumin $<35 \mathrm{~g} / \mathrm{A}$ & 1.63 & 1.072 .49 & $\theta .02$ \\
\hline & Total bilirubin $\geq 20 \mu \mathrm{mo} 1 / 4$ & 1.63 & 1.022 .62 & $\theta .04$ \\
\hline \multirow[t]{2}{*}{ Hepatic resection RFS } & Total bilirubin $>20 \mu \mathrm{mol} / 4$ & 2.18 & 1.353 .51 & $\theta .004$ \\
\hline & MVI & 1.58 & $1.03-2.43$ & 0.04 \\
\hline \multirow[t]{7}{*}{ Transplantation $O S$} & MVI & 2.01 & 1.422 .83 & $<0.0001$ \\
\hline & Non boundary type in CT & 1.80 & 1.202 .72 & 0.005 \\
\hline & $\mathrm{GGT} \geq 230 \mathrm{U} A$ & 1.70 & 1.122 .59 & $\theta .01$ \\
\hline & Tumor number $>3$ & 1.59 & $1.11-2.28$ & 0.01 \\
\hline & Creatinine $>80 \mu \mathrm{mol} / 4$ & 1.54 & $1.10-2.15$ & 0.01 \\
\hline & Tumor size $\geq 30 \mathrm{~mm}$ & 1.52 & $1.09-2.13$ & $\theta .01$ \\
\hline & Age $>60$ & 1.46 & $1.04-2.04$ & 0.03 \\
\hline \multirow[t]{5}{*}{ Transplantation DFS } & Tumor size $\geq 30 \mathrm{~mm}$ & 3.83 & $1.96-7.51$ & $<0.0001$ \\
\hline & MVI & 3.07 & $1.63-5.79$ & 0.0005 \\
\hline & $\mathrm{GGT} \geq 230 \mathrm{U} / 4$ & 2.66 & $1.35-5.25$ & 0.005 \\
\hline & AFP $\geq 100 \mathrm{ng} / \mathrm{ml}$ & 2.29 & $1.17-4.50$ & 0.02 \\
\hline & Non-boundary type & 2.14 & $1.14-3.90$ & $\theta .02$ \\
\hline
\end{tabular}

\begin{tabular}{lllll}
\hline & & $\begin{array}{l}\text { Hazard } \\
\text { ratio }\end{array}$ & $95 \% \mathrm{CI}$ & $P$-value \\
\hline Hepatic resection OS & Tumor number $>3$ & 2.73 & $1.14-5.52$ & 0.03 \\
& MVI & 2.63 & $1.72-4.05$ & $<0.0001$ \\
& Albumin $<35 \mathrm{~g} / 1$ & 1.82 & $1.21-2.76$ & 0.004 \\
\hline Hepatic resection RFS & Tumor number $>3$ & 2.77 & $1.35-5.01$ & 0.007 \\
& MVI & 1.98 & $1.44-2.70$ & $<0.0001$ \\
\hline Transplantation OS & MVI & 2.35 & $1.69-3.27$ & $<0.0001$ \\
& Age $\geq 52$ & 1.67 & $1.13-2.56$ & 0.01 \\
& Tumor size $\geq 40 \mathrm{~mm}$ & 1.52 & $1.06-2.16$ & 0.02 \\
\hline Transplantation RFS & Tumor size $\geq 40 \mathrm{~mm}$ & 4.43 & $2.40-8.17$ & $<0.0001$ \\
& MVI & 3.22 & $1.73-6.17$ & 0.0002 \\
& Non-boundary type & 1.77 & $1.02-3.25$ & 0.04 \\
\hline
\end{tabular}


457 RR, relative risk; $\mathrm{CI}$, confidence interval; OS, overall survival; RFS, recurrence-free 458 survival; MVI, microvascular invasion; GGT, gamma-glutamyltransferase; AFP, 459 alfa fetoprotein.

460 Variables (age, gender, body mass index, diabetes, alcohol, HBs-Ag, HBV-DNA, 461 HCV-Ab, HCV-RNA, Child-Pugh, MELD score, platelet count, albumin, total bilirubin, 462 prothrombin time-international normalized ratio, creatinine, AST, ALT, GGT 463 gamma-glutamyltransferase, ALP, NLR, AFP alfa-fetoprotein, tumor size, tumor 464 number, transfusion, non-boundary type, tumor differentiation, MVI, satellite lesion, 465 tumor capsulation and surgical margin) were subjected to univariate analysis. 
Table 2 Univariate and multivariate analyses of preoperative risk factors for

468 microvascular invasion in the training cohort

\begin{tabular}{|c|c|c|c|c|c|c|c|}
\hline & & \multicolumn{3}{|c|}{ Univariate analysis } & \multicolumn{3}{|c|}{ Multivariate analysis } \\
\hline & & $\begin{array}{l}\text { No MVI } \\
(\mathrm{n}=386) \\
\text { No, }(\%)\end{array}$ & $\begin{array}{l}\text { MVI } \\
(\mathrm{n}=251) \\
\text { No, }(\%)\end{array}$ & $P$ value & $\mathrm{RR}$ & $95 \% \mathrm{CI}$ & $P$ value \\
\hline Gender & $\begin{array}{c}\text { Male } \\
\text { Female }\end{array}$ & $\begin{array}{c}320(82.9) \\
66(17.1)\end{array}$ & $\begin{array}{c}216(86.1) \\
35(13.9)\end{array}$ & 0.24 & & & \\
\hline Age & $\geq 52$ & $309(80.0)$ & $188(74.9)$ & 0.13 & n.s. & & \\
\hline HBs-Ag & + & $59(15.8)$ & $40(16.3)$ & 0.82 & & & \\
\hline HBV-DNA & $\geq 4 \log$ & $5(1.3)$ & $9(3.7)$ & 0.06 & n.s. & & \\
\hline $\mathrm{HCV}-\mathrm{Ab}$ & + & $142(36.8)$ & $100(39.8)$ & 0.44 & & & \\
\hline HCV-RNA & Positive & $59(18.1)$ & $\begin{array}{c}52 \\
(22.3)\end{array}$ & 0.22 & & & \\
\hline Cirrhosis & + & $60(15.5)$ & $43(17.1)$ & 0.60 & & & \\
\hline Child Pugh & $\begin{array}{l}\text { A } \\
\text { B } \\
\text { C }\end{array}$ & $\begin{array}{c}213(56.5) \\
134(35.5) \\
30(8.0)\end{array}$ & $\begin{array}{c}129(54.2) \\
96(40.3) \\
13(5.5)\end{array}$ & 0.31 & & & \\
\hline MELD score & $\geq 10$ & $133(34.7)$ & $84(33.6)$ & 0.77 & & & \\
\hline Body mass index & $\geq 25$ & $202(54.2)$ & $122(49.8)$ & 0.30 & & & \\
\hline Alcohol & + & $100(25.9)$ & $53(21.1)$ & 0.16 & n.s. & & \\
\hline Diabetes & + & $101(26.2)$ & $74(29.4)$ & 0.36 & & & \\
\hline Previous TACE & + & $256(66.3)$ & $146(58.2)$ & 0.04 & n.s. & & \\
\hline Previous LAT & + & $56(14.5)$ & $30(12.0)$ & 0.35 & & & \\
\hline Previous HR & + & $19(4.9)$ & $18(7.2)$ & 0.24 & & & \\
\hline Platelet $\left(\times 10^{4} / \mu \mathrm{l}\right)$ & $>23$ & $50(13.1)$ & $62(25.0)$ & 0.0002 & n.s. & & \\
\hline $\begin{array}{l}\text { Total-Bilirubin } \\
(\mu \mathrm{mol} / \mathrm{l})\end{array}$ & $\geq 18$ & $212(55.1)$ & $133(53.0)$ & 0.61 & & & \\
\hline Albumin (g/l) & $\geq 35$ & $159(43.4)$ & $83(35.4)$ & 0.05 & n.s. & & \\
\hline PT-INR & $\geq 1.30$ & $181(46.9)$ & $102(40.6)$ & 0.12 & n.s. & & \\
\hline NLR & $\geq 3.2$ & $89(24.3)$ & $91(38.7)$ & 0.0002 & 1.86 & $1.26-2.75$ & 0.002 \\
\hline $\begin{array}{l}\text { Creatinine } \\
(\mu \mathrm{mol} / \mathrm{l})\end{array}$ & $\geq 113$ & $37(9.6)$ & $31(12.3)$ & 0.27 & & & \\
\hline GGT (U/l) & $\geq 79$ & $225(59.1)$ & $159(64.9)$ & 0.14 & n.s. & & \\
\hline $\operatorname{ALP}(\mathrm{U} / \mathrm{l})$ & $\geq 122$ & $128(35.0)$ & $108(44.3)$ & 0.02 & n.s. & & \\
\hline
\end{tabular}




\begin{tabular}{lccccccc} 
AST (U/l) & $\geq 62$ & $148(38.3)$ & $130(51.8)$ & 0.0008 & 1.53 & $1.08-2.17$ & 0.02 \\
ALT (U/l) & $\geq 40$ & $194(50.5)$ & $146(58.2)$ & 0.06 & n.s. & & \\
AFP (ng/ml) & $\geq 100$ & $45(11.9)$ & $82(33.1)$ & $<0.0001$ & 3.05 & $1.98-4.70$ & $<0.0001$ \\
$\begin{array}{l}\text { Image results } \\
\begin{array}{l}\text { Largest Tumor } \\
\text { size in image } \\
(\mathrm{mm})\end{array}\end{array}$ & $\geq 40$ & $116(30.0)$ & $133(53.0)$ & $<0.0001$ & 1.98 & $1.38-2.84$ & 0.0002 \\
$\begin{array}{l}\text { Tumor number in } \\
\text { image }\end{array}$ & $\geq 2$ & $168(43.5)$ & $106(42.2)$ & 0.75 & & & \\
$\begin{array}{l}\text { Tumor number in } \\
\text { image }\end{array}$ & $>3$ & $28(7.2)$ & $33(13.1)$ & 0.01 & n.s. & & \\
$\begin{array}{l}\text { Non-boundary } \\
\text { type }\end{array}$ & Yes & $98(29.4)$ & $112(52.3)$ & $<0.0001$ & 1.91 & $1.29-2.82$ & 0.001 \\
\hline
\end{tabular}

469 MVI, microvascular invasion; RR, relative risk; CI, confidence interval; HBs-Ag,

470 hepatitis B surface antigen; HCV-ab, hepatitis C virus antibody; TACE, transcatheter

471 arterial chemoembolization; LAT, local ablation therapy; HR, hepatic resection;

472 PT-INR, prothrombin time-international normalized ratio; NLR,

473 neutrophil-to-lymphocyte ratio; GGT, gamma-glutamyltransferase; ALP, alkaline

474 phosphatase; AST, aspartate aminotransferase; ALT, alanine aminotransferase; AFP,

475 alfa-fetoprotein.

476 
477 Table 3 Predictive model for microvascular invasion based on multivariate logistic

478 regression analysis

\begin{tabular}{|c|c|c|c|c|c|c|}
\hline $\begin{array}{l}\text { Number of } \\
\text { positive } \\
\text { factors }\end{array}$ & $\mathrm{AFP} \geq 100$ & $\begin{array}{c}\text { Tumor size } \geq \\
40\end{array}$ & $\begin{array}{c}\text { Non-boundary } \\
\text { type }\end{array}$ & NLR $\geq 3.2$ & $\mathrm{AST} \geq 62$ & $\begin{array}{c}\text { MVI probability } \\
(\%)\end{array}$ \\
\hline 5 & + & + & + & + & + & 86.9 \\
\hline \multirow[t]{5}{*}{4} & + & + & + & + & - & 81.4 \\
\hline & + & + & + & - & + & 78.3 \\
\hline & + & + & - & + & + & 77.7 \\
\hline & + & - & + & + & + & 77.1 \\
\hline & - & + & + & + & + & 68.3 \\
\hline \multirow[t]{10}{*}{3} & + & + & + & - & - & 70.4 \\
\hline & + & + & - & + & - & 69.6 \\
\hline & + & - & + & + & - & 68.9 \\
\hline & + & + & - & - & + & 65.5 \\
\hline & + & - & + & - & + & 64.7 \\
\hline & + & - & - & + & + & 63.8 \\
\hline & - & + & + & + & - & 58.7 \\
\hline & - & + & + & - & + & 54.0 \\
\hline & - & + & - & + & + & 53.0 \\
\hline & - & - & + & + & + & 52.3 \\
\hline \multirow[t]{10}{*}{2} & + & + & - & - & - & 55.5 \\
\hline & + & - & + & - & - & 54.7 \\
\hline & + & - & - & + & - & 53.7 \\
\hline & + & - & - & - & + & 49.0 \\
\hline & - & + & + & - & - & 43.6 \\
\hline & - & + & - & + & - & 42.6 \\
\hline & - & - & + & + & - & 41.9 \\
\hline & - & + & - & - & + & 38.1 \\
\hline & - & - & + & - & + & 37.3 \\
\hline & - & - & - & + & + & 36.4 \\
\hline \multirow[t]{5}{*}{1} & + & - & - & - & - & 38.7 \\
\hline & - & + & - & - & - & 28.8 \\
\hline & - & - & + & - & - & 28.2 \\
\hline & - & - & - & + & - & 27.4 \\
\hline & - & - & - & - & + & 23.8 \\
\hline 0 & - & - & - & - & - & 17.0 \\
\hline
\end{tabular}

479 AFP, alfa-fetoprotein; NLR, neutrophil-to-lymphocyte ratio; AST, aspartate

480 aminotransferase; MVI, microvascular invasion. 


\section{Table 4}

483 Relationship between MVI probability based on the model and actual MVI rate

\begin{tabular}{|c|c|c|c|c|c|c|}
\hline \multirow{2}{*}{$\begin{array}{c}\text { MVI } \\
\text { probability, } \\
\%\end{array}$} & \multicolumn{2}{|l|}{ Training cohort } & \multicolumn{2}{|l|}{ Validation cohort } & \multicolumn{2}{|l|}{ Total cohort } \\
\hline & $\begin{array}{l}\text { Actual MVI } \\
\text { rate, } \%\end{array}$ & $p$ value & $\begin{array}{l}\text { Actual MVI } \\
\text { rate, } \%\end{array}$ & $p$ value & $\begin{array}{c}\text { Actual MVI } \\
\text { rate, } \%\end{array}$ & $p$ value \\
\hline$\leq 30$ & $\begin{array}{c}22.4 \\
(56 / 250)\end{array}$ & $0.001^{\dagger}$ & $\begin{array}{c}24.5 \\
(37 / 151)\end{array}$ & $0.0009^{\dagger}$ & $\begin{array}{c}23.2 \\
(93 / 401)\end{array}$ & $<0.0001^{\dagger}$ \\
\hline$>30-50$ & $\begin{array}{c}37.8 \\
(51 / 135)\end{array}$ & $0.0002 \ddagger$ & $\begin{array}{c}47.1 \\
(32 / 68)\end{array}$ & $0.30^{\ddagger}$ & $\begin{array}{c}40.9 \\
(83 / 203)\end{array}$ & $0.0001^{\ddagger}$ \\
\hline$>50-70$ & $\begin{array}{c}63.6 \\
(63 / 99)\end{array}$ & $0.17 \pi$ & $\begin{array}{c}57.5 \\
(23 / 40)\end{array}$ & $0.02 \pi$ & $\begin{array}{c}61.9 \\
(86 / 139)\end{array}$ & $0.02 \pi$ \\
\hline$>70$ & $\begin{array}{c}75.0 \\
(36 / 48)\end{array}$ & & $\begin{array}{c}92.9 \\
(13 / 14)\end{array}$ & & $\begin{array}{c}79.0 \\
(49 / 62)\end{array}$ & \\
\hline
\end{tabular}

$484 \dagger^{\dagger} \leq 30$ vs $>30-50,{ }^{\ddagger}>30-50$ vs $>50-70,{ }^{\text {I/ }}>50-70$ vs $>70$

485 MVI, microvascular invasion.

486 
488 Figure 1. Overall survival curves for HCC patients who underwent HR (A) or LT (C), 489 stratified according to the presence or absence of MVI. Recurrence-free survival curves 490 for HCC patients who underwent HR (B) or LT (D), stratified according to the presence 491 or absence of MVI.

492 Figure 2. Calibration plots comparing predicted and actual MVI probabilities among 493 the training cohort (A), the validation cohort (B), HR patients in the training cohort (C), 494 and transplantation patients in the training cohort (D). The dotted line indicates the ideal 495 prediction and the black line is the bias-corrected prediction with 400 bootstraps.

496 Figure 3. Overall (A) and recurrence-free survival (B) curves in HCC patients who 497 underwent HR according to MVI probability ( $<50 \%$ vs $\geq 50 \%$ ) based on the model.

498 Overall (C) and recurrence-free survival (D) curves in HCC patients who underwent LT 499 according to MVI probability ( $<50 \%$ vs $\geq 50 \%$ ) based on the model. 


\section{A HR patients}

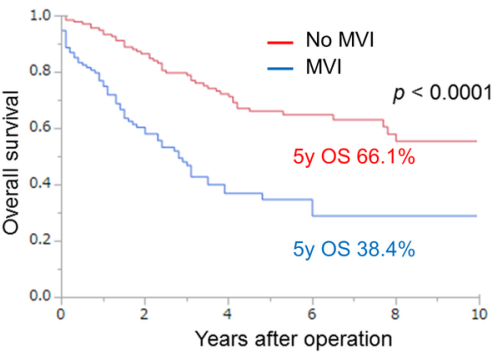

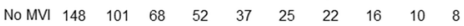

$\begin{array}{lllllllllll}\text { MVI } & 117 & 42 & 25 & 16 & 15 & 8 & 4 & 3 & 2 & 2\end{array}$

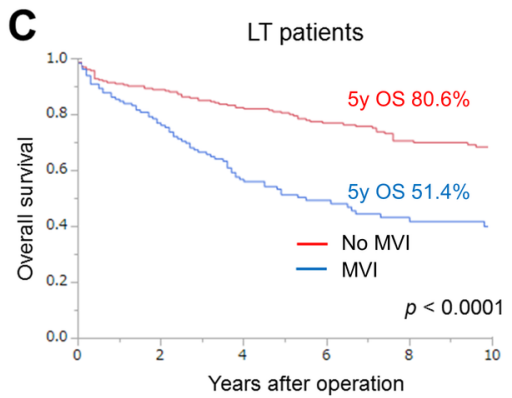

$\begin{array}{lllllllllll}\text { No MVI } & 238 & 217 & 211 & 196 & 184 & 162 & 137 & 124 & 106 & 85\end{array}$ $\begin{array}{lllllllllll}\text { MVI } & 134 & 111 & 97 & 84 & 68 & 55 & 43 & 37 & 32 & 27\end{array}$
B

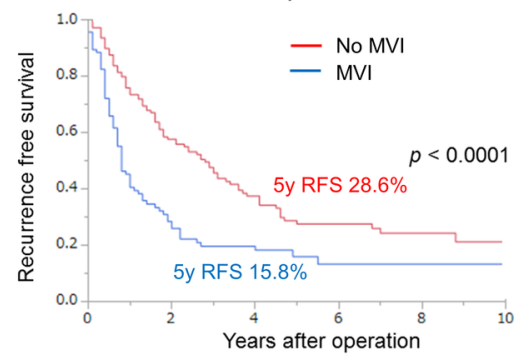

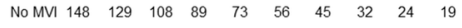

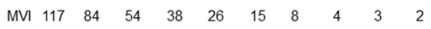
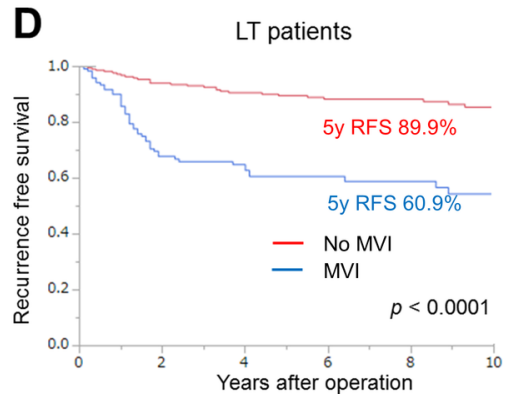

$\begin{array}{lllllllllll}\text { No MVI } & 238 & 214 & 204 & 190 & 180 & 157 & 135 & 122 & 105 & 92\end{array}$ $\begin{array}{lllllllllll}\text { MVI } & 134 & 102 & 75 & 67 & 64 & 47 & 39 & 33 & 30 & 25\end{array}$ 
A

The training cohort

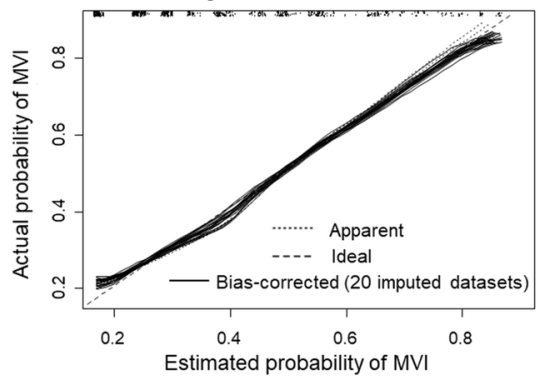

C

HR patients among the validation cohort

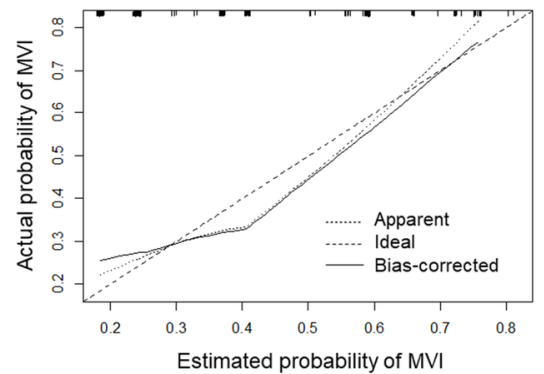

B

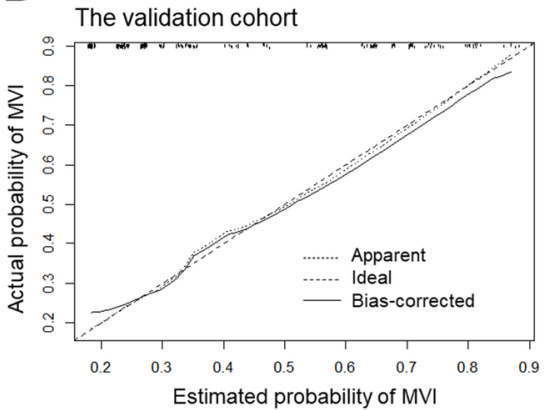

D

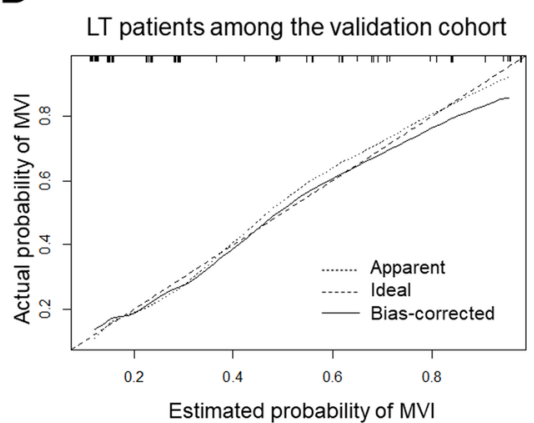



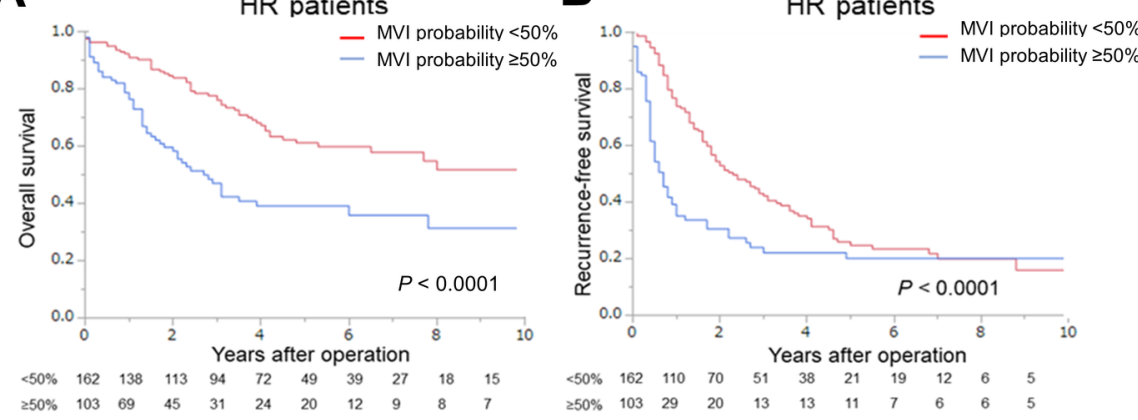

\section{C}

\section{LT patients}

D
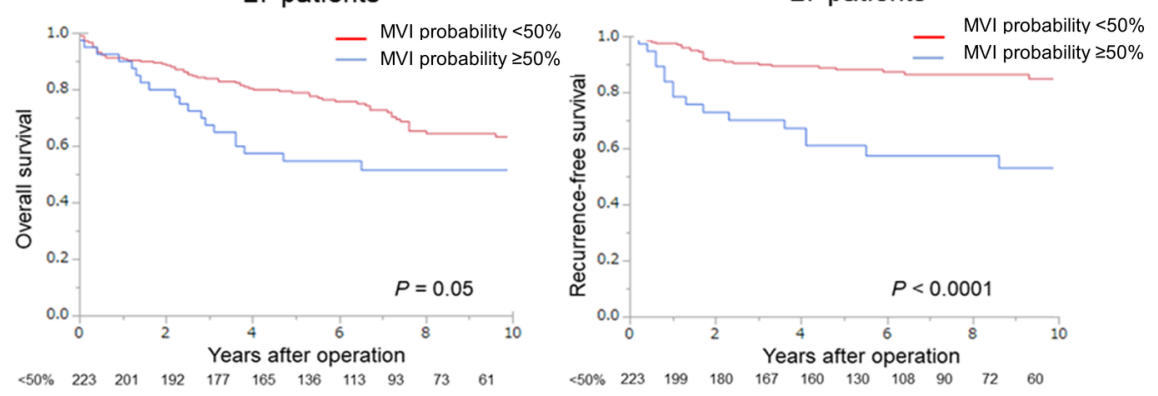

LT patients 